Open Access Full Text Article

REVIEW

\title{
Practical guidance for the use of cyclosporine ophthalmic solutions in the management of dry eye disease
}

This article was published in the following Dove Press journal:

Clinical Ophthalmology

\section{Rodrigo Carlos de Oliveira Steven E Wilson}

Cole Eye Institute, Cleveland Clinic, Cleveland, $\mathrm{OH}$, USA
Correspondence: Steven E Wilson

Cole Eye Institute, Cleveland Clinic, I-32, 9500 Euclid Ave, Cleveland, OH, USA

Email wilsons4@ccf.org

\begin{abstract}
Dry eye disease (DED) is a multifactorial disease of ocular surface and tear film, and is a common disorder treated by eye care providers. It is well established that ocular surface inflammation has an important role in the pathophysiology of DED and that antiinflammatory cyclosporine A (CsA) improves the treatment outcomes of most patients with DED. The purpose of this review is to provide guidance for practitioners in the use of topical CsA for the management of DED to improve patient satisfaction and the quality of life.
\end{abstract}

Keywords: keratoconjunctivitis sicca, dry eye disease, cyclosporine A

\section{Background}

Dry eye disease (DED) is a common ophthalmic disorder that affects more than 15 million people in the United States ${ }^{1}$ and $5-50 \%$ of the global population. ${ }^{2}$ DED has higher prevalence among adults over age 40 , and especially in women - likely due to hormonal factors. ${ }^{2,3}$ The term DED describes a chronic, multifactorial disease that is commonly associated with increased osmolarity of tear film and inflammation of ocular surface and underlying tissues. ${ }^{4}$ Individuals with this disorder experience eye symptoms, including discomfort, pain, burning, foreign body sensation, and visual disturbances. ${ }^{4}$ DED negatively impacts a patient's quality of life $^{2}$ and is estimated to result in almost $\$ 4$ billion annual costs in the United States. ${ }^{5}$

DED is caused by an increased evaporation of the tear film (evaporative type) and/or reduced tear production (aqueous deficient type) ${ }^{4,6}$ Regardless of the primary cause, it is recognized that a self-perpetuating inflammatory cycle underlies the pathophysiology of DED. ${ }^{7-9}$ DED is accompanied by an unstable and hyperosmolar tear film, which has been shown to activate an innate inflammatory immune response of the ocular surface epithelium and subconjunctival tissues involving resident immune cells. ${ }^{10}$ Associated inflammatory mediators induce apoptosis of conjunctival and corneal cells, and also impair lacrimal gland function, further decreasing tear production and leading to a pernicious cycle that worsens the symptoms of DED. ${ }^{7,8,11,12}$ Evidence has shown that T-cells are key contributors to the pathophysiology of dry eye and an adaptive CD4+ Tcell immune response follows the initial innate immune response. ${ }^{13,14}$ The ultimate goal of DED management is to restore ocular surface homeostasis by breaking this pathophysiological cycle and preventing its recurrence. ${ }^{15}$

Control of ocular surface inflammation has been a major contributor to improved DED treatment outcomes. ${ }^{15}$ Long-term use of topical steroids in these 
cases has clinical limitations due to their potential side effects, although short-term use of these medications can be a useful adjuvant in the initiation of treatments or for episodic worsening of symptoms and signs. ${ }^{16,17}$ Conversely, the chronic use of cyclosporine A (CsA) has been shown to be an effective and safe therapeutic strategy for managing the majority of DED patients. ${ }^{18-22}$

\section{CsA: mechanism of action in DED}

CsA was discovered in the early 1970s, originally as an antifungal agent derived from the fungi Tolypocladium inflatum and Beuveria nevus. This fungal metabolite was later found to have a potent immunosuppressive activity. ${ }^{23}$ CsA is an inhibitor of calcineurin - an activator of T-cells -and it prevents T-cell production of inflammatory cytokines and disrupts the immune-mediated inflammatory response. $^{14,24}$ The immunomodulatory activity of CsA reduces DED-induced inflammation associated with the corneal and conjunctival epithelium, accessory lacrimal glands, and subconjunctival tissues and increases conjunctival goblet cell density and tear production. ${ }^{25-28}$ Moreover, CsA prevents apoptotic cell death by binding to cyclophilin $\mathrm{D}$, thereby inhibiting the opening of pores on the mitochondria in response to cellular stress or damage. $^{29}$ As a result, CsA increases the natural production of tears in patients whose tear production is suppressed due to ocular inflammation associated with keratoconjunctivitis sicca (KCS).

\section{CsA ophthalmic solution: pharmacological properties}

CsA is a neutrally charged and hydrophobic molecule with low aqueous solubility — which makes it challenging to formulate a safe and effective ocular drug delivery system for the drug. ${ }^{30}$ CsA ophthalmic solutions were initially formulated in oil-based solvents such as castor oil or corn oil, which were first studied in the early 1980s to inhibit rabbit corneal allograft rejection. ${ }^{31}$ However, the oils used to deliver CsA produce side effects such as blurred vision, burning and stinging, and are poorly tolerated by patients. In addition, these oils provide low bioavailability of CsA. Therefore, the use of CsA in these oils for management of human ophthalmic conditions has decreased in favor of emulsions such as that developed for Restasis. $^{30,32}$

Restasis (Allergan, Inc., Irvine, CA, USA) is an anionic castor oil-in-water emulsion with $0.05 \% \mathrm{CsA}$ and was the first cyclosporine eye drop approved by US Food and Drug Administration (FDA) in 2003 for KCS treatment. Restasis was approved based on a statistically significant improvement in tear production greater than $10 \mathrm{~mm}$ of wetting in 5 mins measured by Schirmer's test in $15 \%$ of the patients, compared to $5 \%$ of the vehicle-treated controls. ${ }^{33}$ A much higher percentage of Restasis-treated patients have some increase in tear production than this very impressive amount, considering that patients enrolled in the Restasis Phase III trial had to have a Schirmer's less than $5 \mathrm{~mm}$ in $5 \mathrm{~min}$ to be entered in the study.

Although oil-in-water CsA emulsions reduce side effects associated with oil-based CsA solutions, they have not eliminated them completely. Research has focused on developing a variety of novel formulations of cyclosporine ophthalmic solutions, such as gel systems, hydrogels, nanoparticles, liposomes, cationic emulsion, and penetration colloidal carriers (micelles). ${ }^{30}$ The aim of these formulations is to improve drug penetration and effectiveness, while at the same time reducing side effects such as stinging. Promising results have been found in using these new drug delivery systems. ${ }^{30}$ However, further research is needed to establish long-term safety and tolerability profiles - and also to verify if they are as efficacious as commercially available oil-in-water-based formulations of CsA.

Ikervis (Santen SAS, Evry, France) is an unpreserved cationic emulsion formulation containing $0.1 \% \mathrm{CsA}$. It was registered in the European Economic Area in 2015 for the treatment of severe keratitis in adults with DED. ${ }^{34}$ Corneal and conjunctival cells are negatively charged at physiological $\mathrm{pH}$, consequently allowing preferential passage of positive ions. ${ }^{35}$ Thus, the cationic vehicle is thought to adhere to and penetrate these cells more easily than anionic solutions. Although there are theoretical advantages based on its novel pharmacokinetics, it also produces complications such as stinging and other dysesthesias (reported in $37 \%$ of the patients treated with the CsA cationic emulsion versus $21 \%$ of the vehicle-treated patients). ${ }^{36}$ Ikervis is not approved in the USA.

More recently, in 2018, Cequa (OTX-101 0.09\%) (Sun Pharmaceutical Ind., Cranbury, NJ, USA) was approved by the FDA for DED management in the United States. This clear, aqueous nanomicellar solution containing $0.09 \% \mathrm{CsA}$ has been reported to deliver therapeutic concentrations of CsA with minimal discomfort to patients. ${ }^{32}$ A list of some ocular formulations of CsA marketed in different countries can be found in Table 1 . 


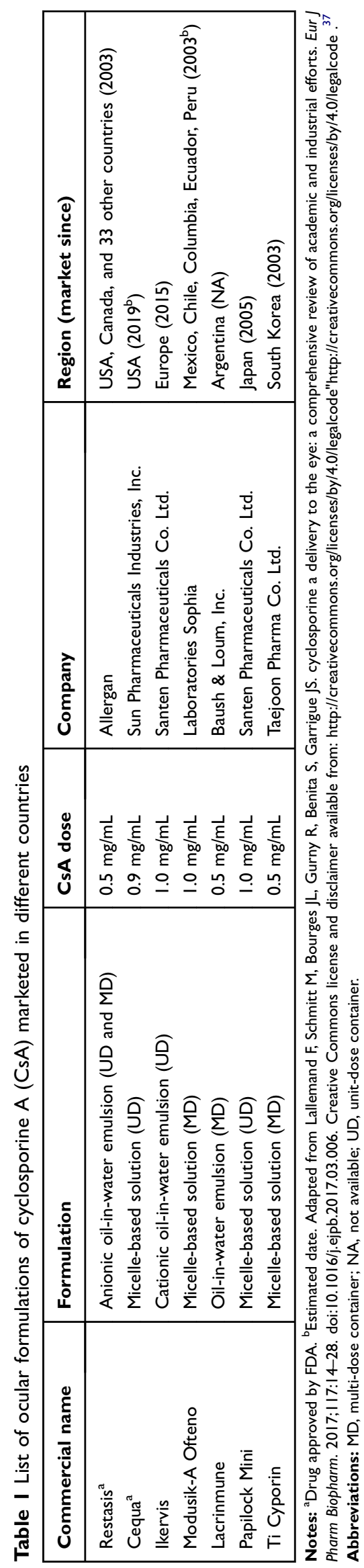

\section{Comparison of FDA-approved ophthalmic CsA treatments}

Several studies have demonstrated that both Restasis and Cequa are efficacious and safe for the management of DED patients, ${ }^{18,38}$ and preliminary studies suggested Cequa may be more effective and better tolerated than Restasis. ${ }^{32,38,39}$ For example, a pharmacokinetic study comparing the ocular CsA concentration between single administration of Restasis $0.05 \%$ and CsA nanomicellar formulation OTX-101 $0.05 \%$ CsA showed significantly higher concentrations of CsA in lacrimal gland, cornea, conjunctiva, sclera, aqueous humor, iris, ciliary body, choroid, and retina (but not in superior eyelid, tears, vitreous humor ,or lens) following administration of OTX-101 $0.05 \% \mathrm{CsA}^{32}$ In another study, OTX-101 was described as the first DED product candidate that significantly improved both conjunctival staining and anesthetized Schirmer's test, in addition to the reduction in corneal staining. ${ }^{39}$ In a Phase III study of OTX-101 0.09\% CsA, the medication produced rapid onset treatment of KCS (efficacy was seen as early as day 28), and only 13 (3.5\%) of OTX-101 subjects reported moderate or severe instillation site pain. ${ }^{38}$ By contrast, Restasis treatment usually takes a longer time to be effective, ${ }^{20,40}$ and in two multicenter studies, approximately $16 \%$ of the patients using the medication reported ocular burning. ${ }^{19}$ Although Cequa has been approved by FDA, it was not available in pharmacies when this article was written and the cost of the medication remains unknown. ${ }^{32}$ Future clinical trials comparing Restasis and Cequa head-to-head will be helpful for clinicians who treat DED.

\section{Management of DED}

A recommended approach for management of DED was proposed by the Tear Film Ocular Society Dry Eye Workshop (DEWS) II in 2017. DEWS II advocated a stepwise therapeutic guide (Figure 1 and Table 2) based on the etiology and severity of the disease. ${ }^{15}$ The severity of disease was categorized on a scale of 1-4, based on symptoms and clinical findings. ${ }^{6}$ Restasis CsA ophthalmic solution was originally approved by the US Food and Drug Administration for the management of moderate-tosevere KCS (severity levels 2-3 in the DEWS guidelines). However, it has been showed that patients with mild dry eye (severity level 1 in the DEWS guidelines) may also benefit from CsA treatment that may reduce the progression of DED severity. ${ }^{41,42}$ The authors agree with this 


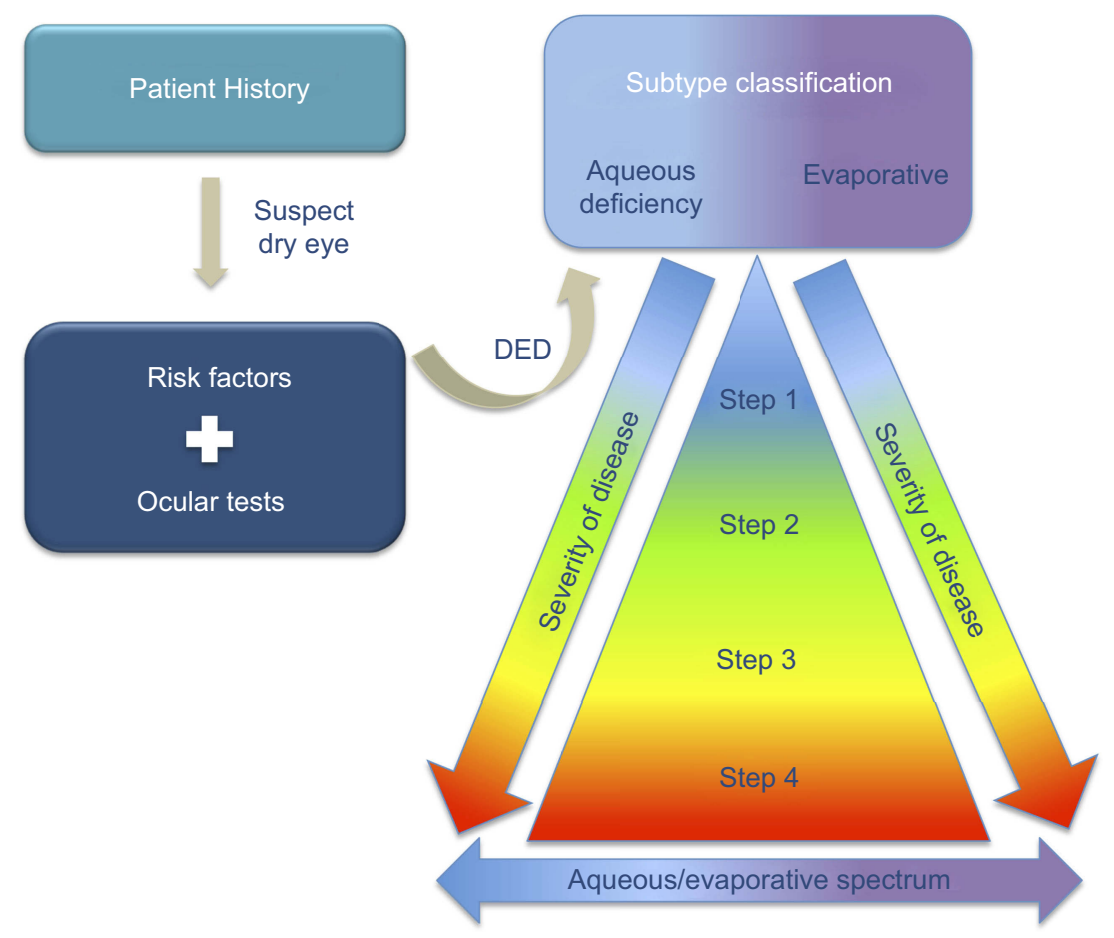

Figure I Dry eye disease (DED) management strategy. Data from Jones et al (2017). ${ }^{15}$

approach since chronic inflammation anywhere in the body damages tissues and early interventions in other inflammatory diseases, such as arthritis and hepatitis, reduce tissue damage. Moreover, DEWS II cautioned that the management algorithm proposed in their report did not represent a rigid stepwise approach. Thus, patients with mild keratoconjunctivitis sicca often benefit from early CsA therapy. It is also critical to determine whether a patient has underlying Sjogren's disease by consulting with a rheumatologist if dry mouth or particularly severe disease is noted since concurrent systemic treatments are often indicated in such patients. ${ }^{43}$

\section{CsA treatment recommendation}

Once the decision has been made to use CsA therapy for DED, the recommended dose of cyclosporine ophthalmic solution is one drop instilled twice a day in each eye. However, several studies have shown that four times a day treatment with CsA can produce a more rapid clinical response during induction of treatment or for patients who have symptoms despite several months of twice a day treatment. ${ }^{44,45}$ Four time a day CsA treatment has not been associated with greater systemic side effects since there is insignificant systemic adsorption of the drug after topical application to the eye. ${ }^{18}$ Thus, in more severe keratoconjunctivitis, more frequent dosing (three or four times per day) may increase efficacy. ${ }^{44,45}$ No therapeutic benefits were found after application of increased concentrations of CsA, but there is increased stinging and other dysesthesias when higher CsA concentrations are used. ${ }^{18}$ Thus, a dose-ranging, randomized trial showed that concentrations of CsA from $0.05 \%$ to $0.1 \%$ yielded the best balance between efficacy and side effects. ${ }^{18}$

\section{Patient education and follow-up}

When used systemically at higher doses, CsA is an immunosuppressive agent. Therefore, education should be provided to patients on the proper use of the medication and monitoring of signs of eye infection. However, in practice, few infections have been noted in patients taking topical CsA, including reactivations of herpes simplex keratitis that were feared by designers of the early trials of Restasis. Patients should be instructed to invert Restasis vials a few times to obtain a uniform, white and opaque emulsion before applying the medication to the eye. Restasis causes transient blurred vision since it is an emulsion. CsA should not be administered into an eye wearing a contact lens because the vehicle adheres to the lens and creates deposits. Contact lenses may be reinserted 15 mins after the administration of the drug. ${ }^{33}$ 


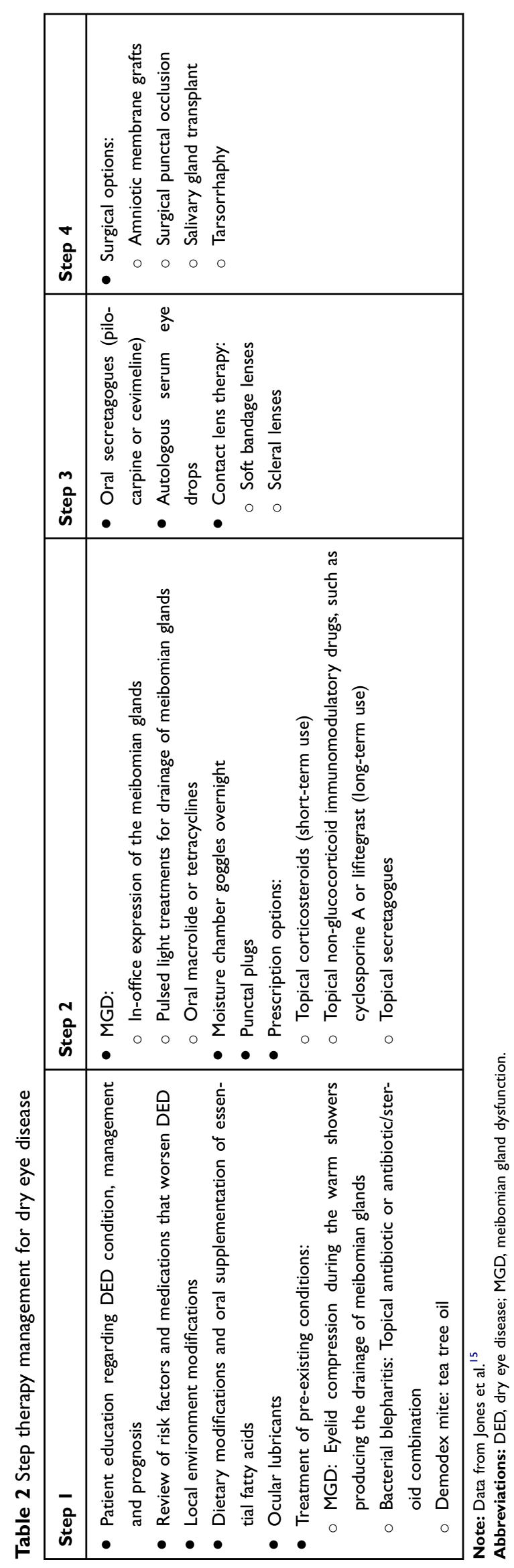


Patients should be warned about the possibility of side effects such as burning, stinging, and conjunctival hyperemia, and be encouraged to continue treatment if these are encountered since they typically dissipate as the ocular surface improves. ${ }^{20}$ Thus, Deveci et $\mathrm{al}^{46}$ showed that patients often noted a reduction in adverse effects with continuous cyclosporine therapy. In addition, a 36-month extension trial reported similar, but lower, burning sensation than previously reported in two Phase III 12-month clinical trials, suggesting that the side effects are reduced by the improved ocular surface. ${ }^{19,20}$ Even with burning or stinging upon instillation, $95.2 \%$ of the patients surveyed reported they could continue cyclosporine therapy and $97.9 \%$ would recommend it to other dry eye patientssuggesting they valued the benefit of the therapy enough to tolerate some discomfort associated with instillation. ${ }^{20}$ These application side effects are often decreased by chilling the medication or applying a non-preserved artificial tear a few minutes prior to the CsA. ${ }^{47}$ Another approach to improve drug compliance is the use of short-term topical corticosteroids, such as $0.5 \%$ loteprednol or $1 \%$ methylprednisolone, two to three weeks prior to or concurrent with long-term $0.05 \% \mathrm{CsA}$ - which reduces stinging, burning, and others side effects of CsA. ${ }^{48}$ This combined therapy can also result in a faster decrease in symptoms, yield a more rapid improvement in Schirmer's test scores, and a decrease in corneal lissamine green or fluorescein staining. ${ }^{49,50}$

\section{Length of treatment}

Keratoconjunctivitis sicca, with or without Sjogren's disease, is a chronic disorder requiring long-term local therapy for the majority of patients. Most studies, including the Restasis phase III clinical trials, ${ }^{19}$ have shown that the CsA treatment can take four to six months to effectively relieve symptoms, although some patients - usually those with milder disease-note improvement within a month. ${ }^{20,40}$ The delay in symptom relief with CsA is thought to occur because CsA does not deactivate previously activated T-cells, but rather prevents new T-cell activation. ${ }^{14,24}$ Cyclosporine typically must be continued for an extended period of time, and in most patients, indefinite treatment is necessary to prevent relapse. ${ }^{15}$ Wilson and Perry, ${ }^{51}$ however, found that a small subgroup of patients appeared to have long-standing elimination of symptoms and signs after a minimum six-month course of Restasis. Thus, if a patient has complete resolution of symptoms and signs of DED after six months of CsA treatment, it was these authors' approach to discontinue the treatment and monitor the patient for a recurrence of symptoms and signs. ${ }^{51}$ They found, however, that $71 \%(12 / 17)$ of the patients subsequently had a return of symptoms and/or signs and resumed long-term treatment. Rao ${ }^{52}$ assessed the progression of DED following discontinuation of CsA after 12 months of treatment. This investigator found that withdrawal of the medication led to the progression of the disease, and, therefore, they encouraged extended maintenance therapy with CsA in patients with chronic KCS. Su et al ${ }^{53}$ proposed a reduction to once-daily CsA application after 12 months of twice-a-day treatment, while maintaining drug efficacy, although $14 \%$ of the patients in that study did not tolerate this reduction. Further studies of the long-term efficacy of CsA treatment for KCS would help guide future therapy.

There have been few reported side effects of topical CsA administration, other than discomfort upon application. For example, a 36-month extension trial of $0.1 \% \mathrm{CsA}$ noted no serious adverse events reported during this treatment period. ${ }^{20}$ Although systemic administration of CsA has been implicated in cutaneous carcinogenic effects, ${ }^{54}$ no relationship between the occurrence of conjunctival neoplasia and use of topical ocular CsA has been noted in numerous prospective studies evaluating the safety and efficacy of topical CsA. This is not surprising because no CSA was detected in the blood of patients treated with $0.05 \%$ CsA (Restasis) twice a day in the phase III clinical trials. $^{19}$

\section{Conclusion}

CsA has been shown to prevent T-cell activation and production of inflammatory cytokines-breaking the inflammatory cycle of DED and increasing the production of tears and conjunctival mucin-producing cells in patients with KCS. A minimum twice-a-day six-month course of CsA is recommended to assess efficacy in patients with KCS. It is critical for patients to understand that DED is a chronic disorder requiring long-term therapy in most patients. Concurrent adjuvant short-term treatment with topical corticosteroids may reduce the side effects and speed up the response to topical CsA treatment. Longterm CsA treatment may delay or halt the progression of DED in some patients.

\section{Acknowledgments}

This study was supported in part by US Public Health Service grants RO1EY10056 (SEW) and P30-EY025585 from the National Eye Institute, National Institutes of 
Health, Bethesda, MD and Research to Prevent Blindness, New York, NY.

\section{Disclosure}

SEW was a consultant for Allergan in developing and implementing the phase III clinical trials for Restasis. The authors report no other conflicts of interest in this work.

\section{References}

1. Dana R, Bradley JL, Guerin A, et al. Estimated prevalence and incidence of dry eye disease based on coding analysis of a large, all-age United States health care system. Am J Ophthalmol. 2019;202:47-54.

2. Stapleton F, Alves M, Bunya VY, et al. TFOS DEWS II epidemiology report. Ocul Surf. 2017;15(3):334-365. doi:10.1016/j.jtos.2017.05.003

3. Epidemiology DEWS subcommittee. The epidemiology of dry eye disease: report of the epidemiology subcommittee of the international dry eye workshop (2007). Ocul Surf. 2007;5(2):93-107. doi:10.1016/ S1542-0124(12)70082-4

4. Craig JP, Nichols KK, Akpek EK, et al. TFOS DEWS II definition and classification report. Ocul Surf. 2017;15(3):276-283. doi:10.1016/j.jtos.2017.05.008

5. McDonald M, Patel DA, Keith MS, Snedecor SJ. Economic and humanistic burden of dry eye disease in Europe, North America, and Asia: a systematic literature review. Ocul Surf. 2016;14(2):144 167. doi:10.1016/j.jtos.2015.11.002

6. Definition and Classification DEWS subcommittee. The definition and classification of dry eye disease: report of the definition and classification subcommittee of the international dry eye workshop (2007). Ocul Surf. 2007;5(2):75-92.

7. Pflugfelder SC, de Paiva CS. The pathophysiology of dry eye disease: what we know and future directions for research. Ophthalmology. 2017;124(11 Suppl):S4-S13. doi:10.1016/j.ophtha.2017.07.010

8. Wilson SE. Inflammation: a unifying theory for the origin of dry eye syndrome. Manag Care. 2003;12(12 Suppl):14-19.

9. Ganesalingam K, Ismail S, Sherwin T, Craig JP. Molecular evidence for the role of inflammation in dry eye disease. Clin Exp Optom. Epub 2019 Jan 10.

10. Baudouin C, Aragona P, Messmer EM, et al. Role of hyperosmolarity in the pathogenesis and management of dry eye disease: proceedings of the OCEAN group meeting. Ocul Surf. 2013;11(4):246-258. doi:10.1016/j.jtos.2013.07.003

11. Pflugfelder SC, De Paiva CS, Moore QL, et al. Aqueous tear deficiency increases conjunctival interferon-gamma (IFN-gamma) expression and goblet cell loss. Invest Ophthalmol Vis Sci. 2015;56 (12):7545-7550. doi:10.1167/iovs.15-17627

12. Coursey TG, Tukler Henriksson J, Barbosa FL, de Paiva CS, Pflugfelder SC. Interferon-gamma-induced unfolded protein response in conjunctival goblet cells as a cause of mucin deficiency in Sjogren syndrome. Am J Pathol. 2016;186(6):1547-1558. doi:10.1016/j. ajpath.2016.02.004

13. Bron AJ, de Paiva CS, Chauhan SK, et al. TFOS DEWS II pathophysiology report. Ocul Surf. 2017;15(3):438-510. doi:10.1016/j. jtos.2017.05.011

14. Kunert KS, Tisdale AS, Stern ME, Smith JA, Gipson IK. Analysis of topical cyclosporine treatment of patients with dry eye syndrome: effect on conjunctival lymphocytes. Arch Ophthalmol. 2000;118 (11):1489-1496.
15. Jones L, Downie LE, Korb D, et al. TFOS DEWS II management and therapy report. Ocul Surf. 2017;15(3):575-628. doi:10.1016/j. jtos.2017.05.006

16. Razeghinejad MR, Myers JS, Katz LJ. Iatrogenic glaucoma secondary to medications. Am J Med. 2011;124(1):20-25. doi:10.1016/j. amjmed.2010.08.011

17. Jobling AI, Augusteyn RC. What causes steroid cataracts? A review of steroid-induced posterior subcapsular cataracts. Clin Exp Optom. 2002;85(2):61-75.

18. Stevenson D, Tauber J, Reis BL. Efficacy and safety of cyclosporin A ophthalmic emulsion in the treatment of moderate-to-severe dry eye disease: a dose-ranging, randomized trial. The cyclosporin a phase 2 study group. Ophthalmology. 2000;107(5):967-974.

19. Sall K, Stevenson OD, Mundorf TK, Reis BL. Two multicenter, randomized studies of the efficacy and safety of cyclosporine ophthalmic emulsion in moderate to severe dry eye disease. CsA phase 3 study group. Ophthalmology. 2000;107(4):631-639.

20. Barber LD, Pflugfelder SC, Tauber J, Foulks GN. Phase III safety evaluation of cyclosporine $0.1 \%$ ophthalmic emulsion administered twice daily to dry eye disease patients for up to 3 years. Ophthalmology. 2005;112 (10):1790-1794. doi:10.1016/j.ophtha.2005.05.013

21. Zhou XQ, Wei RL. Topical cyclosporine A in the treatment of dry eye: a systematic review and meta-analysis. Cornea. 2014;33(7):760767. doi:10.1097/ICO.0000000000000123

22. Wan KH, Chen LJ, Young AL. Efficacy and safety of topical $0.05 \%$ cyclosporine eye drops in the treatment of dry eye syndrome: A systematic review and meta-analysis. Ocul Surf. 2015;13(3):213-225.

23. Kashani S, Mearza AA. Uses and safety profile of ciclosporin in ophthalmology. Expert Opin Drug Saf. 2008;7(1):79-89. doi:10.1517/14740338.7.1.79

24. Stern ME, Beuerman RW, Fox RI, Gao J, Mircheff AK, Pflugfelder SC. The pathology of dry eye: the interaction between the ocular surface and lacrimal glands. Cornea. 1998;17(6):584-589.

25. Moon I, Kang HG, Yeo A, et al. Comparison of ocular surface mucin expression after topical ophthalmic drug administration in dry eyeinduced mouse model. J Ocul Pharmacol Ther. 2018;34(9):612-620. doi:10.1089/jop.2018.0005

26. Moore CP, McHugh JB, Thorne JG, Phillips TE. Effect of cyclosporine on conjunctival mucin in a canine keratoconjunctivitis sicca model. Invest Ophthalmol Vis Sci. 2001;42(3):653-659.

27. Kunert KS, Tisdale AS, Gipson IK. Goblet cell numbers and epithelial proliferation in the conjunctiva of patients with dry eye syndrome treated with cyclosporine. Arch Ophthalmol. 2002;120(3):330-337.

28. Pflugfelder SC, De Paiva CS, Villarreal AL, Stern ME. Effects of sequential artificial tear and cyclosporine emulsion therapy on conjunctival goblet cell density and transforming growth factorbeta2 production. Cornea. 2008;27(1):64-69. doi:10.1097/ ICO.0b013e318158f6dc

29. Li Y, Johnson N, Capano M, Edwards M, Crompton M. CyclophilinD promotes the mitochondrial permeability transition but has opposite effects on apoptosis and necrosis. Biochem J. 2004;383(Pt 1):101-109. doi:10.1042/BJ20040669

30. Agarwal P, Rupenthal ID. Modern approaches to the ocular delivery of cyclosporine A. Drug Discov Today. 2016;21(6):977-988. doi:10.1016/j.drudis.2016.04.002

31. Hunter PA, Wilhelmus KR, Rice NS, Jones BR. Cyclosporin A applied topically to the recipient eye inhibits corneal graft rejection. Clin Exp Immunol. 1981;45(1):173-177.

32. Mandal A, Gote V, Pal D, Ogundele A, Mitra AK. Ocular pharmacokinetics of a topical ophthalmic nanomicellar solution of cyclosporine (Cequa(R)) for dry eye disease. Pharm Res. 2019;36(2):36. doi:10.1007/s11095-018-2556-5

33. Restasis (cyclosporine ophthalmic emulsion) $0.05 \%$ [prescribing information]. CA: Allergan, Inc.; 2017; https://www.allergan.com/ assets/pdf/restasis_pi.pdf. Accessed February 12, 2019. 
34. Hoy SM. Ciclosporin ophthalmic emulsion 0.1\%: a review in severe dry eye disease. Drugs. 2017;77(17):1909-1916. doi:10.1007/ s40265-017-0834-x

35. Liaw JH, Rojanasakul YY, Robinson JR. The effect of drug charge type and charge-density on corneal transport. Int J Pharm. 1992;88 (1-3):111-124. doi:10.1016/0378-5173(92)90308-O

36. Leonardi A, Van Setten G, Amrane M, et al. Efficacy and safety of $0.1 \%$ cyclosporine A cationic emulsion in the treatment of severe dry eye disease: a multicenter randomized trial. Eur J Ophthalmol. 2016;26(4):287-296. doi:10.5301/ejo.5000779

37. Lallemand F, Schmitt M, Bourges JL, Gurny R, Benita S, Garrigue JS. cyclosporine a delivery to the eye: a comprehensive review of academic and industrial efforts. Eur $J$ Pharm Biopharm. 2017;117:14-28. doi:10.1016/j.ejpb.2017.03.006

38. Luchs J. Phase 3 clinical results of cyclosporine $0.09 \%$ in a new nanomicellar ophthalmic solution to treatment keratoconjunctivitis sicca. American society of cataract and refractive surgery (ASCRS) annual meeting; 2018; Washington, DC.

39. Tauber J, Schechter BA, Bacharach J, et al. A phase II/III, randomized, double-masked, vehicle-controlled, dose-ranging study of the safety and efficacy of OTX-101 in the treatment of dry eye disease. Clin Ophthalmol. 2018;12:1921-1929. doi:10.2147/OPTH.S175065

40. Stonecipher K, Perry HD, Gross RH, Kerney DL. The impact of topical cyclosporine A emulsion $0.05 \%$ on the outcomes of patients with Keratoconjunctivitis sicca. Curr Med Res Opin. 2005;21 (7):1057-1063. doi:10.1185/030079905X50615

41. Perry HD, Solomon R, Donnenfeld ED, et al. Evaluation of topical cyclosporine for the treatment of dry eye disease. Arch Ophthalmol. 2008;126(8):1046-1050. doi:10.1001/archopht.126.8.1046

42. Chun YH, Beak JU, Kim HS, Na KS. Topical cyclosporine pretreatment of ocular surface in allogeneic hematopoietic stem cell transplant recipients. J Ocul Pharmacol Ther. 2018;34(9):628-632. doi:10.1089/jop.2018.0006

43. Kuklinski E, Asbell PA. Sjogren's syndrome from the perspective of ophthalmology. Clin Immunol. 2017;182:55-61. doi:10.1016/j. clim.2017.04.017
44. Dastjerdi MH, Hamrah P, Dana R. High-frequency topical cyclosporine $0.05 \%$ in the treatment of severe dry eye refractory to twice-daily regimen. Cornea. 2009;28(10):1091-1096. doi:10.1097/ICO.0b013e3181a16472

45. Gire AI, Karakus S, Ingrodi SM, Akpek EK. Frequent dosing of topical cyclosporine A for severe ocular surface disease. J Ocul Pharmacol Ther. 2016;32(3):150-154. doi:10.1089/jop.2015.0078

46. Deveci H, Kobak S. The efficacy of topical $0.05 \%$ cyclosporine A in patients with dry eye disease associated with Sjogren's syndrome. Int Ophthalmol. 2014;34(5):1043-1048. doi:10.1007/s10792-014-9901-4

47. Deveney T, Asbell PA. Patient and physician perspectives on the use of cyclosporine ophthalmic emulsion $0.05 \%$ for the management of chronic dry eye. Clin Ophthalmol. 2018;12:569-576.

48. Sheppard JD, Scoper SV, Samudre S. Topical loteprednol pretreatment reduces cyclosporine stinging in chronic dry eye disease. J Ocul Pharmacol Ther. 2011;27(1):23-27. doi:10.1089/jop.2010.0085

49. Sheppard JD, Donnenfeld ED, Holland EJ, et al. Effect of loteprednol etabonate $0.5 \%$ on initiation of dry eye treatment with topical cyclosporine 0.05\%. Eye Contact Lens. 2014;40(5):289-296. doi:10.1097/ ICL.0000000000000049

50. Byun YJ, Kim TI, Kwon SM, et al. Efficacy of combined $0.05 \%$ cyclosporine and $1 \%$ methylprednisolone treatment for chronic dry eye. Cornea. 2012;31(5):509-513. doi:10.1097/ICO.0b013e31818c69ef

51. Wilson SE, Perry HD. Long-term resolution of chronic dry eye symptoms and signs after topical cyclosporine treatment. Ophthalmology. 2007;114 (1):76-79. doi:10.1016/j.ophtha.2006.05.077

52. Rao SN. Reversibility of dry eye deceleration after topical cyclosporine 0.05\% withdrawal. J Ocul Pharmacol Ther. 2011;27(6):603609. doi:10.1089/jop.2011.0073

53. Su MY, Perry HD, Barsam A, et al. The effect of decreasing the dosage of cyclosporine A $0.05 \%$ on dry eye disease after 1 year of twice-daily therapy. Cornea. 2011;30(10):1098-1104. doi:10.1097/ ICO.0b013e318206caee

54. Rouimi F, Bouillot A, Baudouin C, Labbe A. [Topical cyclosporine A and risk of ocular surface neoplasia]. J Fr Ophtalmol. 2018;41 (2):122-128. doi:10.1016/j.jfo.2017.09.005
Clinical Ophthalmology

\section{Publish your work in this journal}

Clinical Ophthalmology is an international, peer-reviewed journal covering all subspecialties within ophthalmology. Key topics include: Optometry; Visual science; Pharmacology and drug therapy in eye diseases; Basic Sciences; Primary and Secondary eye care; Patient Safety and Quality of Care Improvements. This journal is indexed on PubMed
Central and CAS, and is the official journal of The Society of Clinical Ophthalmology (SCO). The manuscript management system is completely online and includes a very quick and fair peer-review system, which is all easy to use. Visit http://www.dovepress.com/ testimonials.php to read real quotes from published authors.

\section{Dovepress}

